\title{
Cytokines in bronchoalveolar lavage fluid in patients with high altitude pulmonary oedema at moderate altitude in Japan
}

Keishi Kubo, Masayuki Hanaoka, Shinji Yamaguchi, Toshihide Hayano, Muneharu Hayasaka, Tomonobu Koizumi, Keisaku Fujimoto, Toshio Kobayashi, Takayuki Honda

\begin{abstract}
Background - The precise mechanism of high altitude pulmonary oedema (HAPE) remains unclear. The purpose of this study was to evaluate the role of cytokines and P-selectin in the development of HAPE which occurred at moderate altitude in Japan.

Methods - The following cellular and biochemical markers and chemotactic cytokines were measured in the bronchoalveolar (BAL) fluid from four patients with HAPE at $2857-3180 \mathrm{~m}$ in the Japanese Alps: total proteins, albumin, lactate dehydrogenase (LDH), and interleukin (IL)$1 \alpha, I L-1 \beta$, IL-1 receptor antagonist (ra), IL-6, IL-8, IL-10, tumour necrosis factor (TNF) $-\alpha$, and the soluble form of Pselectin.
\end{abstract}

Results - At admission there were significant increases in the levels of total cells, especially macrophages and neutrophils, total protein, albumin and LDH when compared with 13 healthy individuals. Furthermore, the levels of IL-1ß, IL-6, IL8 , and TNF- $\alpha$ were also considerably increased but returned quickly to the normal ranges or were not detected after recovery. The levels of IL-1 $\alpha, I L-10$, and P-selectin did not change.

Conclusions - These results suggest that an inflammatory process almost identical with acute respiratory distress syndrome (ARDS) may occur in HAPE, but that these changes are transient and are not associated with any increase in $\mathbf{P}$-selectin levels in the BAL fluid.

(Thorax 1996;51:739-742)

Keywords: cytokines, bronchoalveolar lavage, high altitude pulmonary oedema.

High altitude pulmonary oedema (HAPE) is a non-cardiogenic pulmonary oedema that occurs in healthy individuals and is seen among those ascending above $2700 \mathrm{~m}$ in the Japanese Alps. ${ }^{1}$ Its precise mechanism remains unresolved. Although the oedema formation of HAPE might be related to the shear forces associated with increased pulmonary vascular pressure, ${ }^{23}$ it is mainly due to increased pulmonary permeability. ${ }^{4}$ Conversely, recent studies $^{5-7}$ of the pathophysiology of adult (or acute) respiratory distress syndrome (ARDS) or acute lung injury, a pulmonary oedema with typically increasing permeability, have revealed that ARDS is characterised by a significant inflammatory component followed by infiltration of mainly neutrophils and macrophages. There are many studies of chemical mediators, chemical cytokines, and adhesion molecules in the bronchoalveolar lavage (BAL) fluid of patients with ARDS..$^{5-7}$ Sakamaki et $a l^{8}$ have recently reported that the level of the soluble form of $P$-selectin is increased in the plasma of patients with ARDS. From its clinical characteristics it is possible that HAPE is one form of acute lung injury, but no data are available concerning these mediators in HAPE. We have measured the levels of chemotactic cytokines and Pselectin in the BAL fluid of patients with HAPE in order to evaluate the role of these mediators in the development of HAPE.

\section{Methods}

PATIENTS

We examined the cellular and biochemical markers and the chemical cytokines in the BAL fluid of four men with HAPE who were admitted to Shinshu University Hospital $(600 \mathrm{~m}$ above sea level) which is located at the foot of the Japanese Alps. All patients had experienced overt symptoms and signs of HAPE while climbing, with fatigue, fever, cough, production of sputum, tachypnoea and dyspnoea, and cyanosis at $2857-3180 \mathrm{~m}$. At admission they showed severe hypoxaemia $\left(\mathrm{PaO}_{2} 4 \cdot 6(2 \cdot 4) \mathrm{kPa}\right.$ in room air), coarse crackles on chest auscultation, with bilateral infiltrates on the chest radiograph and computed tomographic scan. The bacteriology of their sputum and BAL fluid was negative. All patients recovered within a week with rest and oxygen inhalation. They had no antibiotics or treatment for heart failure. We also studied 13 healthy individuals (eight men) with a median age of 49 years (range 24-67 years) as controls.
Received 20 November 1995 Returned to authors Revised version received 28 February 1996 Accepted for publication 12 March 1996

First Department of
Medicine
K Kubo
M Hanaoka
S Yamaguchi
T Hayano
M Hayasaka
T Koizumi
K Fujimoto
T Kobayashi
Central Clinical
Laboratories
T Honda
Shinshu University
School of Medicine,
3-1-1 Asahi,
Matsumoto 390, Japan
Correspondence to:
Dr K Kubo.
Received 20 November 1995
Returned to authors
30 January 1996
Revised version received
28 February 1996
Accepted for publication
12 March 1996


Analysis of bronchoalveolar lavage fluid in patients with high altitude pulmonary oedema (HAPE)

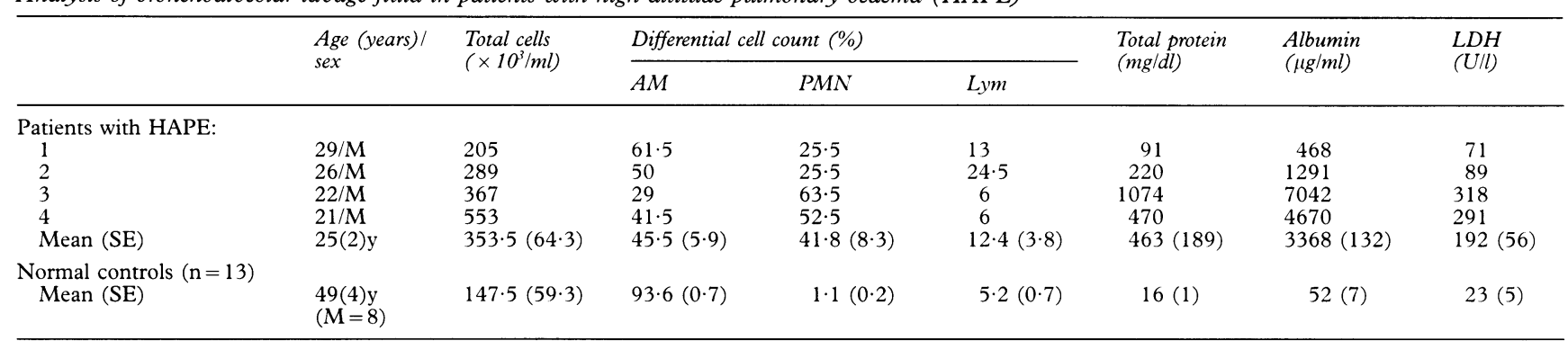

$\mathrm{AM}=$ alveolar macrophages $\mathrm{PMN}=$ neutrophils; $\mathrm{Lym}=$ lymphocytes $\mathrm{LDH}=$ lactate dehydrogenase.

This study was performed according to the criteria set out in the Helsinki Declaration, and free and informed consent was obtained from all patients and normal individuals.

BRONCHOALVEOLAR LAVAGE AND CELL COUNTS The BAL study was performed on days 1-3 after admission in all patients and at recovery in three of them (cases 2, 3, and 4). Subcutaneous injections of atropine $(0.5 \mathrm{mg})$ and pethidine hydrochloride $(0.5 \mathrm{mg} / \mathrm{kg})$ were given. Lignocaine ( $2 \%$ solution) was sprayed in the oral pharynx and upper airway for local anaesthesia. A fibreoptic bronchoscope (Olympus BF 1T, ED $6 \mathrm{~mm}$, Olympus Co., Tokyo, Japan) was wedged in the B4 or B5 segmental bronchus. Three $50 \mathrm{ml}$ aliquots of sterile normal saline warmed to $37^{\circ} \mathrm{C}$ were instilled into the lung and each was then removed by gentle suction. The mean retrieval of the instilled saline in BAL fluid at admission was $50 \cdot 0(7 \cdot 0) \%$. The lavage fluid was filtered through a gauze, and one small aliquot was set aside for counting total cell numbers and another was spun in a cytometer at $500 \mathrm{rpm}$ for five minutes and stained by the May-Grunwald-Giemsa method to identify cell populations. Two hundred cells were identified to determine absolute cell counts, and the counts were expressed as a percentage of the 200 cells. The remaining fluid was stored frozen at $-70^{\circ} \mathrm{C}$ for later biochemical analysis assay for BAL constituents.

ASSAY FOR CONSTITUENTS OF BAL FLUID

The concentrations of total protein, albumin, and lactate dehydrogenase $(\mathrm{LDH})$ in the BAL fluid were measured using the pyrogallol red method, an immunoturbidimetric assay, and the NAD oxidoreductase method, respectively. The chemotactic cytokines listed below and the soluble form of P-selectin were measured by ELISA methods using kits obtained from the following laboratories: Interleukin(IL)- $1 \alpha$, Otsuka Pharmaceutical Ltd, Tokushima, Japan; IL-1 $\beta$, IL-6 and tumour necrosis factor(TNF)- $\alpha$, R \& D Systems Co., Minneapolis, Minnesota, USA; IL-1 receptor antagonist (ra), Amersham Life Science, Buckinghamshire, UK; IL-8, Toray Fuji Bionics, Tokyo, Japan; IL-10, Bio Source International, Camarillo, California, USA; P-selectin (GMP-140), Takara Shuzo Biotechnology Research Laboratories, Tokyo, Japan. The ELISA kits
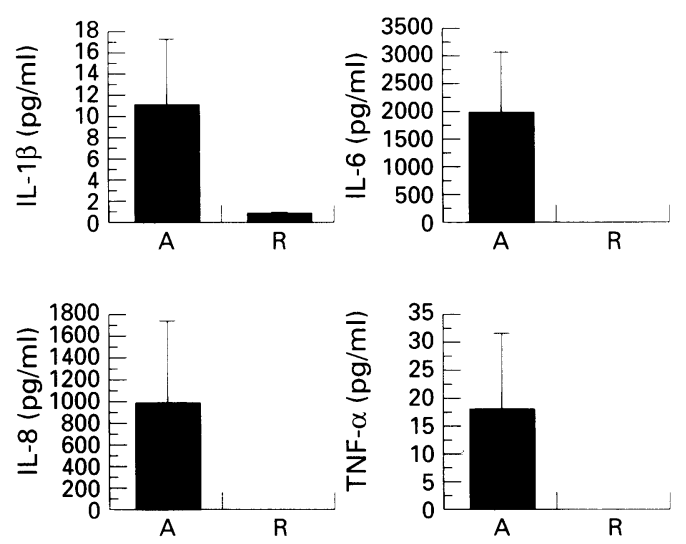

Concentrations of interleukin (IL) $-1 \beta, I L-6, I L-8$, and tumour necrosis factor (TNF)- $\alpha$ in bronchoalveolar lavage fluid in the four patients with HAPE at admission $(A)$ and at recovery $(R)$. Values are means (SE).

for IL-1 $\alpha$, IL-1 $\beta$, IL-1 ra, IL-6, IL-8, IL-10, $\mathrm{TNF}-\alpha$, and P-selectin have recently been used and the precision of the assays determined. ${ }^{8}$

The values are expressed as means (SE). The Student's $t$ test was used for the statistical analysis and a $\mathrm{p}$ value of $<0.05$ was considered significant.

\section{Results}

The results of analysis of the BAL fluid at admission of the four patients with HAPE, together with those for the 13 normal control subjects, are shown in the table, and the concentrations of IL- $1 \beta$, IL- 6 , IL- 8 , and TNF- $\alpha$ in the BAL fluid at admission and following recovery are shown in the figure. At admission the patients showed markedly increased levels of total cells $\left(353.5(64.3) \times 10^{3} / \mathrm{ml}\right)$, total protein $(463(189) \mathrm{mg} / \mathrm{dl})$, albumin (3368 (132) $\mu \mathrm{g} / \mathrm{ml}$ ), and $\mathrm{LDH}(192$ (56) U/l) compared with those of the normal individuals $(147.5$ $(59 \cdot 3) \times 10^{3} / \mathrm{ml}, 16$ (1) $\mathrm{mg} / \mathrm{dl}, 52(7) \mu \mathrm{g} / \mathrm{ml}$, and 23 (5) U/l, respectively). As a percentage of the total cells in the BAL fluid macrophages, neutrophils, and lymphocytes constituted $45 \cdot 5$ $(5 \cdot 9) \%, 41.8(8 \cdot 3) \%$, and $12 \cdot 4(3 \cdot 8) \%$, respectively. The levels of IL-1 $\beta(11 \cdot 1(7 \cdot 1) \mathrm{pg} /$ $\mathrm{ml})$, IL-6 $(1981 \cdot 3(1250 \cdot 0) \mathrm{pg} / \mathrm{ml})$, IL-8 $(983 \cdot 1$ $(879.6) \mathrm{pg} / \mathrm{ml})$, and TNF- $\alpha(18.2(15 \cdot 4) \mathrm{pg} /$ $\mathrm{ml})$ were also markedly increased. At recovery the cellular and biochemical markers and chemotactic cytokines quickly returned to normal levels. The level of IL-1 ra in BAL fluid was $3653.5(1434.6) \mathrm{pg} / \mathrm{ml}$ at admission and 
$408 \cdot 7(243 \cdot 9) \mathrm{pg} / \mathrm{ml}$ at recovery. Neither IL$1 \alpha$ nor IL-10 was detected at admission or after recovery. At admission the concentration of $\mathrm{P}$ selectin in the BAL fluid was $106 \mathrm{ng} / \mathrm{ml}$ in one patient (patient 3), but P-selectin was not detected in the other three patients.

\section{Discussion}

A study of the BAL fluid of six patients who developed HAPE after climbing Mt McKinley in Alaska ${ }^{4}$ reported markedly increased numbers of total cells, with alveolar macrophages and neutrophils comprising $67 \%$ and $25 \%$, respectively, and increased levels of total protein, albumin, and large molecular weight proteins (IgM). The present study also showed similar results, although the percentage of neutrophils was particularly high $(42 \%)$ and the percentage of macrophages was lower (46\%). The discrepancy between the percentage of neutrophils in the BAL fluid in our study and that of Schoene et $a l^{4}$ may be explained by several factors. The conditions under which BAL was performed were completely different, with Schoene et al performing their study on Mt McKinley at $4400 \mathrm{~m},{ }^{4}$ while our study was carried out in patients who were rescued from the Japanese Alps and admitted to hospital at $600 \mathrm{~m}$ above sea level. As a result, there was a longer time lag in our study between the development of HAPE and the BAL study. The temperature was also different, so that the inflammatory process of HAPE may have been more developed in our study. Nevertheless, the results of these two studies suggest that HAPE is due to an increase in lung permeability. The cell counts and percentage of neutrophils in the BAL fluid from patients with ARDS are remarkably high, constituting almost $80 \%$ of the total cell population, ${ }^{7}$ so the cell counts and percentages of neutrophils in the BAL fluid from patients with HAPE are clearly lower than those in ARDS. Schoene et $a l^{4}$ have also noted that alveolar macrophages play an important part in the development of HAPE through the release of leukotriene $\mathrm{B} 4$, a predominant neutrophil chemotactic factor.

The main finding of the present study is that levels of IL-1 $\beta$, IL-6, IL-8, and TNF- $\alpha$ in the BAL fluid of patients with HAPE are significantly increased at admission, but these cytokines are no longer detectable following recovery. IL-1 ra levels were raised at both admission and following recovery. The roles of those cytokines which are increased in the development of HAPE are complicated. IL-1, IL-6, IL-8, and TNF- $\alpha$ are potent chemoattractants of neutrophils and regulate neutrophil adhesion receptors. These substances appear to be of prime importance in ARDS, ${ }^{5-7}$ so it is likely that a similar inflammatory process occurs in HAPE. IL- $1 \beta$ is presumed to function as an extracellular cytokine, though IL-1 $\alpha$ remains in the cytosol and appears to function as an autocrine or paracrine messenger. ${ }^{9}$ IL- $1 \beta$ levels in BAL fluid are increased in patients with ARDS, ${ }^{10}$ and our study has shown that they are also raised in patients with HAPE. Levels of IL-1 ra were raised on admission and also following recovery when its level had declined somewhat. IL-1 ra levels in BAL fluid seem to increase in response to the increase in IL- $1 \beta$ because this substance binds equally to the receptors of IL- $1 \alpha$ and IL- $1 \beta .^{9}$

A number of adhesion molecules have recently been found to play an important part in neutrophil adhesion to the endothelium during the inflammation process. ${ }^{11} \mathrm{P}$-selectin, located on both vascular endothelial cells and platelets, has been shown to be one of these neutrophilendothelium cell adhesion molecules. ${ }^{11}$ Sakamaki et $a l^{8}$ reported that plasma levels of the soluble form of P-selectin were increased in patients with ARDS and acute lung injury, especially in those who subsequently died, and they concluded that this substance may serve as a useful indicator of the severity of acute lung injury. In the present study P-selectin was detected in BAL fluid at admission in one patient (patient 3) but not in the other three patients. The former patient showed more significant permeability in terms of the levels of total protein, albumin and $\mathrm{LDH}$, and also the higher counts of neutrophils in the BAL fluid. Further studies are needed to examine the relationship between the P-selectin levels in BAL fluid or plasma and the severity of HAPE.

The pathogenesis of ARDS or acute lung injury consists of two pathways: the direct effects of an insult on the pulmonary epithelium and endothelium and the indirect result of an acute systemic inflammatory response such as sepsis, severe pneumonia, and endotoxaemia. ${ }^{5-7}$ Many studies have investigated the indirect effects of cytokines and the adhesion molecules mentioned above in ARDS or acute lung injury. Sepsis, endotoxin, and other substances initially stimulate the production of IL1 and TNF- $\alpha$ from macrophages or monocytes, and these cytokines, in turn, stimulate the production of other cytokines. We consider that HAPE is one type of acute lung injury caused by the direct effects of the lung cells. The factors related to the development of HAPE are twofold - namely, environmental and individual factors. The environmental factors are unique to high altitude and include hypoxia, hypobaria, and cold. Furthermore, exercise at high altitude is an important factor. There have recently been several in vitro and in vivo studies concerning the relationship between these factors and cytokines or adhesion molecules. In the in vitro studies severe hypoxia $\left(\mathrm{Po}_{2} 1 \cdot 9-2 \cdot 4\right.$ $\mathrm{kPa}$ ) led to time-dependent release of IL-8 from human endothelial cells. ${ }^{12}$ During strenuous exercise monocytes are activated and release IL-6 and TNF- $\alpha .{ }^{13}$ The individual factors include the susceptibility to hypoxia and exercise and their conditions during a period at high altitude. We consider that there is variability in the susceptibility ${ }^{1415}$ of individuals to HAPE, including a lower ventilatory response to hypoxia and the pulmonary haemodynamic hyperresponsiveness to hypoxia, hypobaria and exercise. We speculate that these variations in susceptibility to HAPE play an important part in its development, which occurs at relatively low altitudes such as the Japanese Alps. It would seem worthwhile to evaluate cellular 
functions and cytokine release in subjects susceptible to HAPE.

It is well known that HAPE resolves very rapidly when patients are transferred to low altitude, and the cellular and biochemical markers in the BAL fluid of our patients quickly returned to their normal ranges. IL-1 $\beta$, IL-6, IL-8, and TNF- $\alpha$ which are increased in ARDS or acute lung injury are also raised in the BAL fluid in patients with HAPE, and their elevations are also transient. The pattern of change in the concentrations of these cytokines at admission is almost identical to that in ARDS, but the change in P-selectin differs.

We thank Mitsubishi Chemical BCL Co (Tokyo, Japan) for the technical assistance in the measurement of cytokines and $\mathrm{P}$ selectin. We also thank Drs S Yoshikawa, S Horie, K Okada T Miyahara, E Sato, H Nomura, S Yamaguchi, T Kaneki, Y Takabayshi, and Y Yamazaki for their generous support of this study.

This work was supported in part by a Grant-in-Aid for Scientific Research, no. 06670606, from the Ministry of Education, Science, and Culture of Japan.

Kobayashi T, Koyama S, Kubo K, Fukushima M, Kusama $\mathrm{S}$. Clinical features of patients with high-altitude pulmonary oedema in Japan. Chest 1985;92:814-21.

2 West JB, Tsukimoto K, Mathieu-Costello O, Prediletto R. Stress failure in pulmonary capillaries. $\mathcal{F}$ Appl Physiol 1991 70:1731-42.
3 Bartsch P, Maggiorini M, Ritter M, Noti C, Vock P, Oelz $O$. Prevention of high-altitude pulmonary oedema by nifedipine. N Engl f Med 1991;325:1284-9.

4 Schoene RB, Swenson ER, Pizzo CJ, Hackett PH, Roach RC, Mills WJ Jr, et al. The lung at high altitude: bronchoalveolar lavage in acute mountain sickness and pulmonary oedema. $\mathcal{F}$ Appl Physiol 1988;64:2605-13.

5 Windsor ACJ, Mullen PG, Fowler AA, Sugerman HJ. Role of the neutrophil in adult respiratory distress syndrome. Br F Surg 1993;80:10-17.

6 St John RC, Dorinsky PM. Immunologic therapy for ARDS, eptic shock, and multiple-organ failure. Chest 1993;103. $932-43$

7 Kollef $\mathrm{MH}$, Schuster DP. The acute respiratory distress syndrome. N Engl f Med 1995;332:27-37.

8 Sakamaki F, Ishizaka A, Handa M, Fujishima S, Urano T, Sayama K, et al. Soluble form of P-selectin in plasma is levated in acute lung injury. Am $\mathcal{f}$ Respir Crit Care Med 1995;151:1821-6.

9 Dinarello CA. Interleukin-1 and interleukin-1 antagonism. Blood 1991;77:1727-52.

10 Suter PM, Suter S, Girardin E, Roux-Lombard P, Grau $\mathrm{GE}$, Dayer J-M. High bronchoalveolar levels of tumor necrosis factor and its inhibitors, interleukin-1, and elastase, in patients with adult respiratory distress syndrome after trauma, shock, or sepsis. Am Rev Respir Dis 1992; 145:1016-22

11 Carlos TM, Harlan JM. Leukocyte-endothelial adhesion molecules. Blood 1994;84:2068-101.

12 Karakurum M, Shreeniwas R, Chen J, Pinsky D, Yan SD Anderson $\mathrm{M}$, et al. Hypoxic induction of interleukin-8 Anderson $\mathrm{M}$, et al. Hypoxic induction of interleukin-8 gene expression in

13 Rivier A, Pene J, Chanez P, Anselme F, Caillaud C, Prefaut $\mathrm{C}$, et al. Release of cytokines by blood monocytes during

14 Matsuzawa Y, Fujimoto K, Kobayashi T, Namushi NR Harada $\mathrm{K}$, Kohno $\mathrm{H}$, et al. Blunted hypoxic ventilatory drive in subjects susceptible to high-altitude pulmonary (1)

15 Kawashima A, Kubo K, Kobayashi T, Sekiguchi M. Hemodynamic responses to acute hypoxia, hypobaria, and exercise in subjects susceptible to high-altitude pulmonary oedema. $f$ Appl Physiol 1989;67:1982-9. 